\title{
BMJ Open The cost-effectiveness of the MobileMums intervention to increase physical activity among mothers with young children: a Markov model informed by a randomised controlled trial
}

\author{
Edward Burn, ${ }^{1}$ Alison L Marshall, ${ }^{1}$ Yvette D Miller, ${ }^{1}$ Adrian G Barnett, ${ }^{1}$ \\ Brianna S Fjeldsoe, ${ }^{2}$ Nicholas Graves ${ }^{1}$
}

To cite: Burn E, Marshall AL, Miller YD, et al. The costeffectiveness of the MobileMums intervention to increase physical activity among mothers with young children: a Markov model informed by a randomised controlled trial. BMJ Open 2015;5:e007226. doi:10.1136/ bmjopen-2014-007226

- Prepublication history for this paper is available online. To view these files please visit the journal online (http://dx.doi.org/10.1136/ bmjopen-2014-007226).

Received 17 November 2014 Revised 26 February 2015 Accepted 27 February 2015

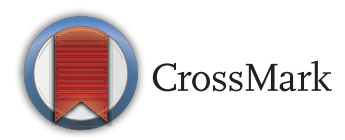

${ }^{1}$ Queensland University of Technology (QUT), School of Public Health and Social Work and Institute of Health and Biomedical Innovation (IHBI), Brisbane, Queensland, Australia

${ }^{2}$ The University of Queensland, School of Population Health, Brisbane, Queensland, Australia

Correspondence to Edward Burn; ea.burn@qut.edu.au

\section{ABSTRACT}

Objectives: To determine the cost-effectiveness of the MobileMums intervention. MobileMums is a 12-week programme which assists mothers with young children to be more physically active, primarily through the use of personalised SMS text-messages.

Design: A cost-effectiveness analysis using a Markov model to estimate and compare the costs and consequences of MobileMums and usual care.

Setting: This study considers the cost-effectiveness of MobileMums in Queensland, Australia.

Participants: A hypothetical cohort of over 36000 women with a child under 1 year old is considered. These women are expected to be eligible and willing to participate in the intervention in Queensland, Australia.

Data sources: The model was informed by the effectiveness results from a 9-month two-arm community-based randomised controlled trial undertaken in 2011 and registered retrospectively with the Australian Clinical Trials Registry (ACTRN12611000481976). Baseline characteristics for the model cohort, treatment effects and resource utilisation were all informed by this trial.

Main outcome measures: The incremental cost per quality-adjusted life year (QALY) of MobileMums compared with usual care.

Results: The intervention is estimated to lead to an increase of 131 QALYs for an additional cost to the health system of 1.1 million Australian dollars (AUD). The expected incremental cost-effectiveness ratio for MobileMums is 8608 AUD per QALY gained.

MobileMums has a $98 \%$ probability of being costeffective at a cost-effectiveness threshold of 64000 AUD. Varying modelling assumptions has little effect on this result.

Conclusions: At a cost-effectiveness threshold of 64000 AUD, MobileMums would likely be a costeffective use of healthcare resources in Queensland, Australia.

Trial registration number: Australian Clinical Trials Registry; ACTRN12611000481976.
Strengths and limitations of this study

- The analysis is informed by the results from a recent two-arm randomised controlled trial of MobileMums and usual care.

- Uncertainty around the costs and consequences of MobileMums and usual care has been quantified and has little effect on the conclusions of the analysis.

- The model's simplicity, with physical activity levels split into only two categories, means that small changes in an individual's activity would likely not be valued.

\section{INTRODUCTION}

Physical inactivity is a leading cause of lost years of healthy life in high-income countries, where chronic diseases are a leading cause of mortality and morbidity. ${ }^{1}$ An insufficient level of physical activity, defined as less than $30 \mathrm{~min}$ of moderate-intensity to vigorous-intensity physical activity on at least 5 days a week, is directly associated with a number of diseases including coronary heart disease, type 2 diabetes, breast cancer and colon cancer. ${ }^{2}$ Physical inactivity is also indirectly linked to the negative health consequences of high body mass and high blood pressure, which include many of the aforementioned chronic conditions. ${ }^{1}$

Fifty-seven per cent of Australia's adult population were insufficiently active in 20112012. ${ }^{3}$ Begg et $a l^{4}$ estimate that $6.6 \%$ of the total disease burden in Australia is caused by physical inactivity, explaining around $24 \%$ of cardiovascular disease and diabetes, and around $6 \%$ of all cancers. Based on these results, Cadilhac et al $\bar{l}$ estimate that each year insufficient physical activity causes 45000 new cases of disease which are associated 
with a loss of 174000 disability-adjusted life-years in Australia. Inequalities in activity levels exist, with inactivity more likely in older people, those of lower socioeconomic status, those outside of major cities and women. ${ }^{6}$ Indeed, women with young children are more likely to be physically inactive than both women with no children ${ }^{78}$ and women with older children, ${ }^{910}$ and it is this group who are the focus of the MobileMums intervention evaluated here.

The MobileMums programme is a 12-week intervention designed to assist women with young children increase their physical activity. The intervention's development has previously been discussed. ${ }^{11}$ MobileMums is initiated with a face-to-face consultation between the participant and a trained behavioural counsellor. The consultation is used to establish rapport between the participant and counsellor, to gather information required to tailor and personalise text-message content and to initiate the process of behaviour change through personalised goal setting. ${ }^{11}$ Participants receive five text-messages per week during weeks $1-4$ of the intervention and four textmessages per week during weeks $5-12$. The messages are personalised based on the participant's name, the name of their counsellor, the participant's goals and their expected rewards and outcomes for achieving these goals. In addition to receiving the text-messages, participants also have access to a programme handbook, an online exercise directory and a Facebook group. They also receive a refrigerator magnet for self-monitoring and standard information brochures on physical activity. As well as requiring behavioural counsellors, delivering the intervention requires programme coordinators to manage the counsellors, assign participants to a counsellor, oversee the text-messages being sent and received, and to organise sending other programme materials to participants.

In Australia health resources are generally allocated on a state or territory basis ${ }^{12}$ and so a decision on whether to fund MobileMums would be made by individual states or territories. The alternative course of action would be to provide usual care. The purpose of this paper is to consider this decision of whether to provide MobileMums or usual care from the perspective of Queensland Health, the government department responsible for managing the public health system in Queensland, Australia.

It is assumed that the overarching objective of Queensland Health is to maximise population health subject to their budget. This, therefore, supports the need for an economic evaluation of MobileMums to consider the intervention's value for money. While this evaluation is specific to the funding decision faced by Queensland Health, it can be expected that the results reported will be directly applicable to similar decisions in other Australian states and territories. The generalisability of the results to other high-income countries may be more limited, for example because of differences in the volume and cost of resource use between countries, ${ }^{13}$ but the results are likely to be of relevance for all countries experiencing high levels of physical inactivity.

\section{METHODS}

\section{Study population}

It is expected that MobileMums would be offered to all women with children under 1 year old in Queensland, Australia, regardless of their current level of physical activity. With 61020 women giving birth in Queensland in 2010 and with 413 fetal deaths, ${ }^{14}$ the number of women eligible for the intervention in 2011 was 60607 . We expect around $60 \%$ of women who were offered the intervention would participate. This is based on the randomised control trial conducted in $2011,{ }^{15} 16$ where of the 511 women assessed for eligibility 306 started the baseline assessment. This gives 36364 women in Queensland who would be eligible and willing to participate in the MobileMums intervention in 2011, and this is the baseline cohort size considered for this study. This participation estimate of $60 \%$ is likely conservative, as the programme would not include the time-consuming assessments that were undertaken purely for research purposes. Given the uncertainty around this estimate, we consider the effects of reducing this cohort size by $50 \%$ to 18182 women, and increasing it by $50 \%$ to 54546 women.

\section{Modelling health outcomes and costs}

A state-based Markov model provides the framework for this analysis and is used to estimate the costs and consequences associated with MobileMums and usual care. The development of the model has been informed by the effectiveness results from a 9-month two-arm community-based randomised controlled trial undertaken in 2011. ${ }^{15}$ A total of 263 women from around Caboolture, Queensland, received usual care $(n=130)$ or the MobileMums intervention $(\mathrm{n}=133) .{ }^{16}$ Data were collected prior to the intervention being received (time 1 -T1: 0 months), after the 12-week MobileMums programme was completed (T2: 3 months) and again after a further 6 month no-contact maintenance period (T3: 9 months). Owing to an administrative error the trial was registered retrospectively with the Australian Clinical Trials Registry (ACTRN12611000481976) and 26 of the trial participants were already receiving MobileMums or usual care by the time of registration. However, none of these participants had passed T2 when the trial was registered.

The main efficacy findings from the trial have been reported in detail by Fjeldsoe et al. ${ }^{16}$ Briefly, while the intervention had a large and statistically significant beneficial effect on activity levels between $\mathrm{T} 1$ and $\mathrm{T} 2$, there was no statistically significant effect at T3, although the estimated increase in activity remained positive. These results suggest that MobileMums can only be expected to have an effect on activity levels in the short-term. Under 
the assumption that only long-term changes in activity levels affect the risk of an individual developing future chronic health conditions, the time horizon of the model used is 2 years.

There are just two states in the model with participants either 'physically inactive' or 'physically active', and an individual is required to be undertaking $30 \mathrm{~min}$ of moderate-intensity to vigorous-intensity physical activity on at least 5 days a week to be classified as active. An effective physical inactivity intervention increases the likelihood that inactive individuals become active (tpImprove) and/or reduces the likelihood that active individuals become inactive (tpRegress). Individuals move between states using monthly cycles, and spending a month as active or inactive has a cost and health outcome associated with it (described below). An outline of the model is shown in figure 1.

\section{Health effects}

To estimate the value for money of MobileMums, health effects are expressed in terms of quality-adjusted lifeyears (QALYs). Given the design of the model used, MobileMums can only affect health-related quality-of life, with no mortality effects. The health-related quality-of-life associated with being physically active or inactive was estimated from participants' responses to SF-12 questionnaires at T1, T2 and T3. Mean imputation was used for missing questionnaire data at each time period (1\% of participants at T1, $13 \%$ at T2, and $32 \%$ at T3). Two errors were made in the printing of the SF-12 questionnaires. First, at T1 one question from the SF-12 was omitted in error, and so scores were randomly generated for this dimension. Second, one of the questions offered one too many potential responses at all time periods, and so those who selected this superfluous response were evenly split and moved into either the next best or next worst choice.

Questionnaire responses were transformed into the EQ-5D, a standardised measure of health outcomes, using an algorithm provided by Gray et $a l^{17}$ which provides utility scores close to group means, especially for individuals not in poor health. This approach generates health-related quality-of-life scores associated with spending a year as physically active or inactive which could range between 0 (equivalent to death) and 1 (equivalent to perfect health). Monthly scores were simply one-twelfth of this. QALYs and costs in the second year

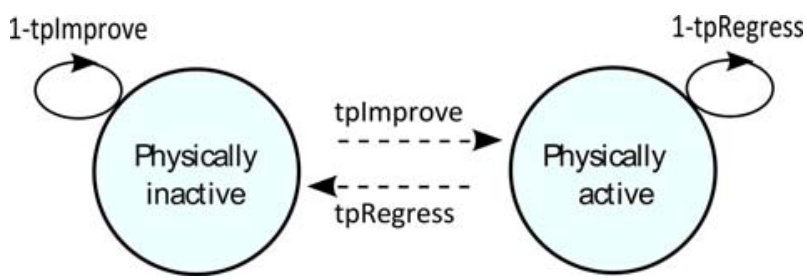

Figure 1 Outline of the Markov model used to estimate the costs and effects of MobileMums and usual care. were discounted at $5 \%$ following the relevant guidelines. $^{1819}$

\section{Costing perspective}

This study is intended to inform decision-making regarding resource allocation across the health system in Queensland. Consequently, a health system perspective is taken, with only the costs borne by the health system included. ${ }^{20}$ While costs falling outside of the health system, such as the cost to participants of purchasing goods or services related to undertaking exercise, may be of interest, they are not are not of direct relevance given the perspective taken here and so have been excluded. All costs reported have been inflated to 2014 Australian dollars (AUD) and any costs accruing in the second year of the model have been discounted at 5\% in line with guidelines for submission to the Medical Services Advisory Committee ${ }^{18}$ and the Pharmaceutical Benefits Advisory Committee ${ }^{19}$ in Australia.

The estimated cost of providing MobileMums across Queensland is based on the costs of delivering the intervention in the randomised controlled trial. ${ }^{16}$ To extrapolate these costs, assumptions have been required concerning number of behavioural counsellors and programme coordinators required for widespread dissemination. It is assumed that counsellors could be assigned to 30 participants per week, while coordinators could cover five counsellors and their participants per week. Counsellors and coordinators are assumed to be health practitioners with, on average, 2 years in their current role and, in terms of Queensland Health's salary scale, ${ }^{21}$ paid at a HP3 (6092 AUD per month) and a HP4 (8150 AUD per month) level, respectively. The costs of developing the computer programme to send text-messages, sending the text-messages and providing other programme materials are assumed to be the same as in the trial.

In addition to the costs of delivering the intervention, the costs relating to participants healthcare use have also been incorporated. If the intervention reduces future healthcare use then the cost saving associated will counterbalance the cost of providing MobileMums. Participants' reported their use of healthcare services at T1, T2 and T3 and the average use of those who were physically active and inactive were estimated. As with the SF-12, mean imputation was used for missing data $(0 \%$ of participants at $\mathrm{T} 1,12 \%$ at T2, and $31 \%$ at T3). The associated costs were estimated using the Medicare Benefits Schedule for July $2011^{22}$ and Australian hospital statistics. $^{23}$

\section{Expected effects}

The purpose of this evaluation is to estimate the expected value for money of the MobileMums intervention, which is indicated by the incremental costeffectiveness ratio (ICER) for MobileMums. This ratio is given by the expected (mean) change in costs associated with the intervention divided by the expected change in 
QALYs. ${ }^{24}$ This ratio can then be compared against a costeffectiveness threshold. The threshold used is 64000 AUD which is based on the estimate by Shiroiwa et $a l^{25}$ of the willingness-to-pay for an additional QALY in Australia. If the cost-effectiveness ratio for MobileMums falls below 64000 AUD then the intervention can be expected to be 'cost-effective'.

\section{Uncertainty}

Parameter uncertainty was quantified using Monte Carlo simulations, with the model evaluated 10000 times, with each simulation involving random draws from each parameter distribution. These distributions are based on the trial data, with transition probabilities and QALYs given beta distributions, while healthcare utilisation and its associated costs assigned gamma distributions and uniform distributions, respectively. This produces 10000 pairs of incremental costs and effects, and these are presented on a cost-effectiveness plane along with the expected costs and effects and the cost-effectiveness threshold. The probability that MobileMums is costeffective is given by the proportion of pairs of incremental costs and benefits at which the intervention would be considered cost-effective. The percentage of pairs where the change in QALYs is positive and the change in costs is negative is equal to the probability that MobileMums is cost-saving. It is also possible to estimate credible intervals around the expected change in costs and QALYs by taking percentiles of the costs and QALYs produced in the Monte Carlo analysis. ${ }^{26}$

Uncertainty also exists surrounding the modelling assumptions. In particular, three areas stand out for particularly onerous assumptions: transition probabilities after 9 months (T3), the number of programme counsellors and coordinators required, and the number of women who would be eligible and willing to participate in the trial. The assumptions used for these areas are the subject of scenario analyses. First, the model is reassessed under the assumption that after T3 all programme activity effects are mitigated entirely, and then again under the assumption that the estimated treatment effect observed at T3 is maintained for a further 15 months, at which point the treatment effect is entirely mitigated. Second, the number of counsellors and coordinators required is increased by $50 \%$ and reduced by $50 \%$. And lastly, increasing the cohort size by $50 \%$ and reducing it by $50 \%$ is considered.

\section{RESULTS}

\section{Average effects}

The input variables are detailed in table 1 . Around $70 \%$ of the women entering the model at $\mathrm{T} 1$ are expected to be physically inactive. Under usual care there is a small and gradual expected positive net movement from inactive to active over time, and after 24 months around $35 \%$ of the initial cohort are expected to be in the active state. The expected effect of MobileMums is to
Table 1 Input variables for the Markov model

\begin{tabular}{|c|c|c|c|}
\hline & Mean & SE & Distribution \\
\hline $\begin{array}{l}\text { Probability of being inactive } \\
\text { at } \mathrm{T} 1\end{array}$ & 0.71 & 0.03 & Beta \\
\hline \multicolumn{4}{|c|}{ Probability of moving from inactive to active (tplmprove) } \\
\hline Usual care (T1 to T2) & 0.20 & 0.04 & Beta \\
\hline MobileMums (T1 to T2) & 0.35 & 0.05 & Beta \\
\hline Usual care (T2 to T3) & 0.14 & 0.04 & Beta \\
\hline MobileMums (T2 to T3) & 0.26 & 0.05 & Beta \\
\hline \multicolumn{4}{|c|}{ Probability of moving from active to inactive (tpRegress) } \\
\hline Usual care (T1 to T2) & 0.43 & 0.08 & Beta \\
\hline MobileMums (T1 to T2) & 0.18 & 0.06 & Beta \\
\hline Usual care (T2 to T3) & 0.33 & 0.07 & Beta \\
\hline MobileMums (T2 to T3) & 0.45 & 0.06 & Beta \\
\hline \multicolumn{4}{|c|}{$\begin{array}{l}\text { Monthly healthcare utilisation costs (2014 AUD per } \\
\text { participant) }\end{array}$} \\
\hline Physically active & 53.30 & 39.20 & $\begin{array}{l}\text { Uniform and } \\
\text { Gamma* }\end{array}$ \\
\hline Physically inactive & 75.40 & 32.62 & $\begin{array}{l}\text { Uniform and } \\
\text { Gamma* }\end{array}$ \\
\hline Cost of delivering & 62.64 & 13.08 & Uniform \\
\hline \multicolumn{4}{|c|}{ MobileMums (2014 AUD per participant) } \\
\hline \multicolumn{4}{|c|}{ EQ5D score } \\
\hline Inactive & 0.78 & 0.01 & Beta \\
\hline Active & 0.81 & 0.01 & Beta \\
\hline
\end{tabular}

${ }^{*} \mathrm{~A}$ uniform distribution for healthcare costs and a gamma distribution for healthcare utilisation.

AUD, Australian dollar.

cause a substantial increase in physical activity over the duration of the 12-week intervention, with $50 \%$ of the participants expected to be in the active state at $\mathrm{T} 2$. Following the intervention gradual reduction in the proportion of active participants each month is expected, until after 16 months whereby the effect of MobileMums has been mitigated entirely. These expected changes in activity levels are presented in figure 2.

Time spent in the active state is expected to provide slightly higher utility than time spent in the inactive state, with a year spent as physically active associated with a health-related quality-of-life score of $0.81 \mathrm{com}$ pared with 0.78 for a year spent as physically inactive. As MobileMums is expected to increase the total number of months spent by the cohort in the active state, the intervention can therefore also be expected to improve health-related quality-of-life. Over 24 months, MobileMums is estimated to lead to an increase of 131 QALYs across the cohort of 36364 women or, equivalently, 0.0036 QALYs per person.

The expected cost of delivering MobileMums to the cohort is 2277950 AUD, or 63 AUD per person. The breakdown for this cost is shown in table 2. Almost half the cost is due to the behavioural counsellors. While there are significant costs associated with setting up the programme, such as the development of a computer programme to send personalised text-messages, these costs are of little consequence with a cohort of 36364 women.

Based on data from the trial it is estimated that active individuals cost the health system 53 AUD a month on 
Figure 2 The expected (mean) effect of MobileMums on activity levels.

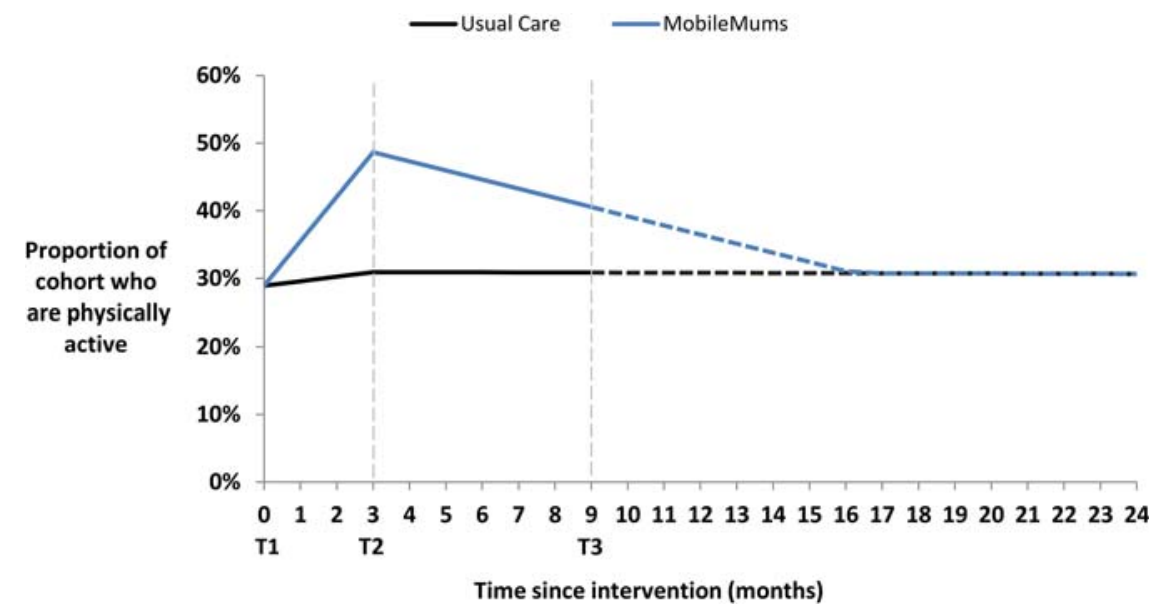

average, while inactive individuals cost 75 AUD per month. As MobileMums reduces the average number of months spent in the inactive state, the cost of delivering the intervention is partly offset by an expected reduction in these healthcare costs. As a result, the total expected incremental cost to the health system from introducing MobileMums is 1124209 million AUD, or 31 AUD per person.

With an expected (mean) incremental cost of 1124209 million AUD and an incremental improvement in health outcomes of 130 QALYs, the costeffectiveness ratio for MobileMums is approximately 8608 AUD per QALY. At a cost-effectiveness threshold of 64000 AUD, the intervention can therefore be expected to be cost-effective.

\section{Uncertainty}

The pairs of incremental costs and consequences produced by the Monte Carlo simulation are shown in figure 3. MobileMums has a $98 \%$ probability of being

\begin{tabular}{lcc}
$\begin{array}{l}\text { Table } 2 \\
\text { Queensland, Australia, in 2014 AUD }\end{array}$ & \\
\hline & $\begin{array}{l}\text { Total cost } \\
\text { (AUD) }\end{array}$ & $\begin{array}{l}\text { Cost per } \\
\text { participant } \\
\text { (AUD) }\end{array}$ \\
\hline & 14204 & 0.39 \\
\hline $\begin{array}{l}\text { Development of the } \\
\text { computer programme for }\end{array}$ & \\
sending automated & & \\
text-messages & & \\
Sending text-messages & 620999 & 17.08 \\
Providing additional & 621388 & 17.08 \\
programme materials & & \\
Behavioural counsellors (24 required) & \\
$\quad$ Salaries & 438628 & 12.06 \\
Equipment & 36231 & 0.99 \\
$\quad$ Travel costs & 388368 & 10.68 \\
Programme coordinators (5 required) & \\
$\quad$ Salaries & 122248 & 3.36 \\
Office costs & 35885 & 0.98 \\
Total & 2277950 & 62.64 \\
\hline AUD, Australian dollar. & & \\
& &
\end{tabular}

cost-effective at a threshold of 64000 AUD (98\% of simulations are below the sloped threshold line). The intervention has around a $19 \%$ probability of being costsaving and health-improving (19\% of simulations are in the south-east quadrant).

The results from the scenario analyses are presented in table 3. None of the changes in assumptions had any substantial effect on the probability that MobileMums is cost-effective at a threshold of 64000 AUD, which remained over $95 \%$ under all scenarios. Changes in the assumption surrounding the maintenance of changes in activity levels into the future did, however, have a substantial effect on the probability that MobileMums is costsaving. If changes were entirely mitigated after 9 months (T3) then the intervention would only have a $1 \%$ chance of being cost-saving, while if the observed difference in activity levels at T3 was maintained for up to 24 months MobileMums would have a $39 \%$ probability of being cost-saving.

\section{DISCUSSION}

\section{Principal findings}

The results from this study suggest the MobileMums intervention would be a cost-effective use of health resources in Queensland, Australia. While the expected health benefits of the intervention are modest, with an average health improvement of only 0.0036 additional QALYs, the cost of the intervention, after taking into account reduced healthcare utilisation, is low at just 31 AUD per person. Consequently, the expected cost-effectiveness ratio is 8608 AUD per QALY, which is far below the estimated willingness to pay for an additional QALY in Australia of 64000 AUD. ${ }^{5}$ Neither parameter nor modelling uncertainty have a substantial effect on this conclusion.

\section{Study strengths and limitations}

This study has been largely informed by the results of a recent 9-month randomised controlled trial. By using a decision-analytic model, it was possible to extrapolate these findings to consider the costs and consequences of 
Figure 3 Cost-effectiveness plane for MobileMums versus usual care with 1000 sets of incremental costs and effects randomly drawn from the 10000 Monte Carlo simulations along with the expected (mean) incremental costs and effects and a cost-effectiveness threshold of 64000 AUD. AUD, Australian dollars; ICER, incremental cost-effectiveness ratio; QALY, quality-adjusted life year.
- Monte Carlo simulations

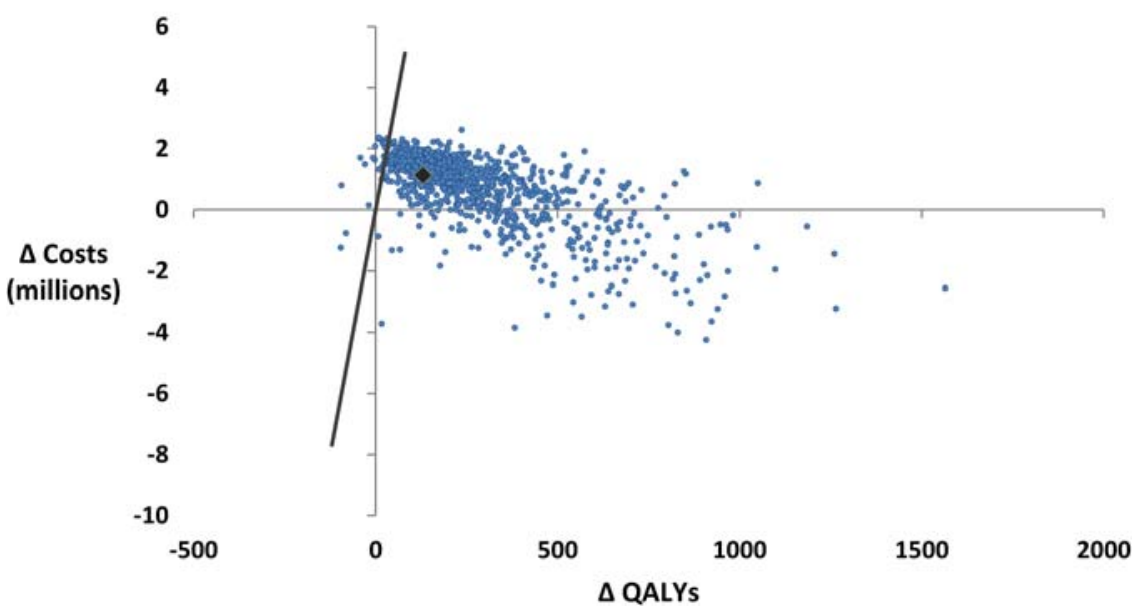

MobileMums if it were offered in practice to a large cohort of women and to account for expected costs and consequences beyond the trial's time horizon. Although several assumptions underpin this approach, they were subjected to sensitivity analyses which have shown them to have little effect on the overall conclusion that the intervention is likely cost-effective.

With the effect of MobileMums on activity levels expected to last for less than 2 years, and under the conservative assumption that only longer-term changes in activity will affect the risk of an individual developing future chronic health conditions, the model used is only required to have a short-time horizon. However, if MobileMums does prompt some long-term improvements in physical activity then the benefits of the intervention will be understated. In addition, while the simplicity of the model used has advantages, particularly for ease of exposition, there are limitations. In particular, only those changes in activity enough to move participants between the two states of the model are captured, with any changes of activity levels within a state overlooked.

\section{Comparison with other studies}

While a number of economic evaluations of physical activity interventions have been undertaken, there is significant methodological heterogeneity making direct comparisons difficult in many cases. Of those studies which use a similar methodology, that is, using a

Table 3 Results from the scenario analyses which examine whether the intervention remains cost-effective for a range of assumptions

\begin{tabular}{|c|c|c|c|c|c|}
\hline \multirow[b]{2}{*}{ Scenario } & \multicolumn{2}{|c|}{$\begin{array}{l}\text { Mean change ( } 95 \% \text { credible interval) caused by } \\
\text { MobileMums }\end{array}$} & \multirow[b]{2}{*}{$\begin{array}{l}\text { Expected } \\
\text { (mean) } \\
\text { ICER }\end{array}$} & \multicolumn{2}{|c|}{$\begin{array}{l}\text { Probability } \\
\text { MobileMums is }\end{array}$} \\
\hline & Total costs (AUD) & QALYs & & $\begin{array}{l}\text { Cost- } \\
\text { effective } \\
(\%)^{\star}\end{array}$ & $\begin{array}{l}\text { Cost- } \\
\text { saving } \\
(\%)\end{array}$ \\
\hline Base case & 1124209 (1 102044 to 1146374$)$ & $131(126$ to 135$)$ & 8608 & 98 & 19 \\
\hline $\begin{array}{l}\text { Changes in activity levels entirely } \\
\text { mitigated at } 9 \text { months (T3) }\end{array}$ & 1363736 (1 363736 to 1372716 & 103 (102 to 105$)$ & 13186 & 97 & 1 \\
\hline $\begin{array}{l}\text { Changes in activity levels } \\
\text { maintained from } 9 \text { months to } 24 \\
\text { months }\end{array}$ & 240173 (217066 to 263281$)$ & 232 (227 to 236$)$ & 1037 & 97 & 39 \\
\hline $\begin{array}{l}\text { Number of counsellors and } \\
\text { coordinators required increased } \\
\text { by } 50 \%\end{array}$ & 1456518 (1434 365 to 1478670$)$ & 131 (126 to 135$)$ & 11152 & 98 & 15 \\
\hline $\begin{array}{l}\text { Number of counsellors and } \\
\text { coordinators required reduced } \\
\text { by } 50 \%\end{array}$ & 823527 (802374 to 844680$)$ & 130 (127 to 134$)$ & 6306 & 98 & 24 \\
\hline $\begin{array}{l}\text { Cohort size increased by } 50 \% \text { to } \\
54546 \text { women }\end{array}$ & 1643613 (1610282 to 1676943$)$ & 196 (190 to 202$)$ & 8390 & 98 & 20 \\
\hline $\begin{array}{l}\text { Cohort size reduced by } 50 \% \text { to } \\
18182\end{array}$ & 585020 (574005 to 596035$)$ & 65 (63 to 67$)$ & 8959 & 98 & 17 \\
\hline
\end{tabular}

${ }^{*}$ At a threshold of 64000 AUD.

AUD, Australian dollars; ICER, incremental cost-effectiveness ratio; QALY, quality-adjusted life year. 
decision-analytic model as a framework for analysis with the cost per quality-adjusted (or disability-adjusted) lifeyear estimated, many of the interventions are found to be cost-effective. For example, the 'green prescription' programme in New Zealand is found to have an incremental cost of 3000 AUD per QALY, $^{27}$ while Cobiac et $a l^{28}$ found a pedometer intervention in Australia to be cost-saving and an internet-based intervention to have an incremental cost of 4000 AUD per QALY. However, the cost-effectiveness of such physical activity intervention is by no means guaranteed. Cobiac $e t a l^{28}$ find that a referral to exercise scheme has an incremental cost of 100000 AUD per QALY, while a 8-week social support programme was found by Roux et $a l^{29}$ to have an incremental cost of 95000 AUD per QALY.

Interestingly, while these other studies typically assumed that the benefit from physical activity interventions was only through reducing the incidence of future chronic diseases, this study demonstrates that they are also likely to produce an immediate improvement in health-related quality-of-life. Active participants in the trial of MobileMums reported higher health-related quality-of-life than those who were physically inactive, so that MobileMums is expected to be cost-effective even without any long-term changes in activity levels. With this immediate improvement in quality-of-life missed in most analyses of physical activity interventions, these studies may well have underestimated the full benefits from effective physical activity interventions.

\section{Policy implications}

Health prevention programmes in Queensland, and across Australia, have recently been going through a period of disinvestment. However, if the goal of the health system is to maximise health outcomes then there seems little reason for prevention health interventions to be treated any differently to a curative intervention. While the MobileMums intervention can only be expected to provide a modest improvement in health-related quality of life for the average participant, it does provide a meaningful improvement in terms of population health. Healthcare resources should be directed to those uses which provide best value for money, that is, the greatest improvement in health outcomes for a given level of cost. Given the relatively low cost of delivering MobileMums, the intervention can be expected to provide good value for money and is likely a cost-effective use of healthcare resources given the estimated willingness-to-pay for an additional QALY in Australia.

Providing the intervention across Australia can be expected to provide a similar level of value for money. Levels of physical inactivity are similar across Australia ${ }^{3}$ and costs, such as those associated with the counsellors and coordinators, should also be comparable. While differences in costs make it more difficult to generalise our results to other countries, the results of this study are still likely to be of relevance in many high-income countries with similarly high levels of physical inactivity. It would seem likely that a programme such as MobileMums would provide good value for money if provided in such countries. However, this is an area where further research is required.

\section{CONCLUSION}

MobileMums can be expected to be a cost-effective use of health resources in Queensland, Australia. If the objective of Queensland Health is to maximise population health outcomes given a finite budget, then MobileMums should be freely provided.

Twitter Follow Adrian Barnett at @aidybarnett

Acknowledgements Computational resources and services used in this work were provided by the High Performance Computer and Research Support Unit, Queensland, University of Technology, Brisbane, Australia.

Contributors ALM, YDM, BSF, AGB and NG conceived and designed the experiments. ALM, YDM, AGB, BSF and NG performed the experiments. EB, $A G B$ and NG analysed the data. EB, ALM, YDM, AGB and NG wrote the paper.

Funding This study was supported by a National Health and Medical Research Council project grant number 614244.

Competing interests None declared.

Ethics approval The trial used to inform this analysis was registered retrospectively with the Australian Clinical Trials Registry (ACTRN12611000481976). Ethical clearance was obtained through the Queensland University of Technology Human Research Ethics Committee (Application number 0900001407).

Provenance and peer review Not commissioned; externally peer reviewed.

Data sharing statement The full data set is available by emailing the first author of the study.

Open Access This is an Open Access article distributed in accordance with the Creative Commons Attribution Non Commercial (CC BY-NC 4.0) license, which permits others to distribute, remix, adapt, build upon this work noncommercially, and license their derivative works on different terms, provided the original work is properly cited and the use is non-commercial. See: http:// creativecommons.org/licenses/by-nc/4.0/

\section{REFERENCES}

1. World Health Organization (WHO). Global health risks: mortality and burden of disease attributable to selected major risks. Geneva: World Health Organization (WHO), 2009.

2. Lee I, Shiroma E, Lobelo F, et al. Impact of physical inactivity on the world's major non-communicable diseases. Lancet 2012;380:219-29.

3. Australian Bureau of Statistics. Australian health survey: first results, 2011-2012. Canberra: Australian Bureau of Statistics, 2012.

4. Begg S, Vos T, Barker B, et al. The burden of disease and injury in Australia 2003. Canberra: Australian Institute of Health and Welfare, 2007.

5. Cadilhac D, Magnus A, Cumming T, et al. The health and economic benefits of reducing disease risk factors. Victoria: VicHealth, 2009.

6. Australian Institute of Health and Welfare. Key indicators of progress for chronic disease and associated determinants. Canberra: Australian Institute of Health and Welfare, 2011.

7. Love E, Rose M, Verhoef M. Women's social roles and their exercise participation. Women Health 1992;19:15-29.

8. Brown W, Mishra G, Lee C, et al. Leisure time physical activity in Australian women: relationship with well being and symptoms. Res Q Exerc Sport 2000;71:206-16.

9. Brown W, Trost S. Life transitions and changing physical activity patterns in young women. AM J Prev Med 2003:25:140-3.

10. Nomaguchi K, Bianchi S. Exercise time: gender differences in the effects of marriage, parenthood, and employment. J Marriage Fam 2004;66:413-30. 
11. Fjeldsoe BS, Miller YD, O'Brien JL, et al. Iterative development of MobileMums: a physical activity intervention for women with young children. Int J Behav Nutr Phys Act 2012;9:151.

12. Biggs A. Health in Australia: a quick guide. Canberra: Parliament of Australia, Department of Parliamentary Services, 2013.

13. Sculpher MJ, Pang FS, Manca A, et al. Generalisability in economic evaluation studies in healthcare: a review and case studies. Health Technol Assess 2004;8:iii-iv, 1-192.

14. Li R, Zeki L, Hilder L, et al. Australia's mothers and babies. Canberra: Australian Institute of Health and Welfare, 2010.

15. Marshall A, Miller Y, Graves B, et al. Moving MobileMums forward: protocol for a larger randomized controlled trial of an improved physical activity program for women with young children. $B M C$ Public Health 2013;13.

16. Fjeldsoe B, Miller Y, Graves N, et al. Randomized controlled trial of an improved version of MobileMums, an intervention for increasing physical activity in women with young children. Ann Behav Med Published Online First 13 Jan 2015.

17. Gray A, Rivero-Arias O, Clarke P. Estimating the association between SF-12 responses and EQ-5D utility values by response mapping. Med Decis Making 2006;26:18-29.

18. Medical Services Advisory Committee. Technical guidelines for preparing assessment reports for the Medical Services Advisory Committee. Canberra: Medical Services Advisory Committee, 2012.

19. Pharmaceutical Benefits Advisory Committee. Guidelines for preparing submissions to the Pharmaceutical Benefits Advisory Committee. Canberra: Pharmaceutical Benefits Advisory Committee, 2013.
20. Claxton K, Walker S, Palmer S, et al. Appropriate perspectives for health care decisions. York: Centre for Health Economics, University of York, 2010.

21. Queensland Health. Health practioners' (Queensland Health) certified agreement. HPEB2. Queensland Health, 2011.

22. Australian Government Department of Health and Ageing. Medicare benefits schedulebook: operating from 01 July 2011. Canberra: Department of Health and Ageing, 2011.

23. Australian Institute of Health and Welfare (AlHW). Australian hospital statistics 2011-12. Health services series no. 50. Canberra: AlHW, 2013.

24. Drummond M, McGuire A. Economic evaluation in health care: merging theory with practice. New York: Oxford University Press, 2001.

25. Shiroiwa T, Sung Y-K, Fukuda T, et al. International survey on willingness-to-pay (WTP) for one additional QALY gained: what is the threshold of cost effectiveness? Health Econ 2009;19:422-37.

26. Briggs A, Sculpher M, Claxton K. Decision modelling for health economic evaluation. New York: Oxford University Press, 2006.

27. Dalziel K, Segal L, Elley R. Cost utility of physical activity in counselling. Aust NZ J Public Health 2005;30:57-63.

28. Cobiac L, Vos T, Barendregt JJ. Cost-effectiveness of interventions to promote physical activity: a modelling study. PLoS Med 2009;6: e1000110.

29. Roux L, Pratt M, Tengs TO, et al. Cost effectiveness of communitybased physical activity interventions. Am J Prev Med 2008;35 (6):578-88. 